\title{
Aftereffects of self-control: The reward responsivity hypothesis
}

\author{
Nicholas J. Kelley \\ Northwestern University \\ Anna J. Finley \\ Brandon J. Schmeichel \\ Texas A\&M University
}

In Press: Cognitive, Affective, and Behavioral Neuroscience

Word Count (main text): 10,617

Acknowledgements: Preparation of this manuscript was supported by National Institute of Health (NIH) grant T32 NS047987 to NJK.

Corresponding Author: Nicholas J. Kelley, Department of Psychology, Northwestern

University, Swift Hall, 2029 Sheridan Road, Evanston, IL, 60208, USA. Email:

nicholasjkelley@gmail.com 


\begin{abstract}
Exercising self-control can be phenomenologically aversive. Insofar as individuals strive to maintain a positive emotional state, one consequence of exercising self-control may thus be a temporarily tuning toward or amplification of reward-related impulses (perhaps arising to countermand the aversive feelings that stem from self-control). Reward-relevant aftereffects are relatively underappreciated in self-control research. In the current paper, we review theory and research pertaining to the idea that exercising self-control increases reward responsivity. First, we review theoretical models of self-control focusing on the relationship between control systems and reward systems. Second, we review behavioral studies regarding the effects of exercising self-control on subsequent reactivity to food, money, drugs, and positive emotional images. Third, we review findings from functional neuroimaging and electroencephalographic research pertaining to the reward responsivity hypothesis. We then call for additional research to integrate how, when, and under what circumstances self-control exertion influences reward processing. Such an endeavor will help to advance research and theory on self-control by offering a more precise characterization of the dynamic interactions between control systems and reward systems.
\end{abstract}

Keywords: Self-control, ego depletion, mental effort, self-regulation, reward, positive affect 


\section{Aftereffects of self-control: The reward responsivity hypothesis}

Motivational systems for approach and avoidance facilitate adaptive responses to rewards (e.g., opportunities to mate or to eat) and threats (e.g., predators), respectively. But approach and avoidance motivations may arise at inopportune times or places, or otherwise contribute to maladaptive behavior. The capacity to override or alter motivated responses thus contributes to behavioral flexibility in humans (e.g., Munakata, Snyder, \& Chatham, 2012; Vaughn, Kopp, Krakow, 1984) as well as in other species, including non-human primates (e.g., Addessi, Paglieri, \& Focaroli, 2011; Amici, Aureli, \& Call, 2008), rats (Eisenberger, Weier, Masterson, \& Theis, 1989), and dogs (Bray, MacLean, \& Hare, 2014; Miller, Pattison, DeWall, RayburnReeves, \& Zentall, 2010; see MacLean et al., 2014).

The ability to override or alter motivated responses (i.e., self-control) is crucial for goaldirected behavior and contributes to many consequential outcomes in humans, including physical health, psychological well-being, ethical decision making, and successful interpersonal relationships (for a review, see Vohs \& Baumeister, 2016). Conversely, failures of self-control can have deleterious consequences in these domains and numerous others. Self-control has thus been of keen interest to philosophers (both ancient and contemporary, see Russell, 2004; Searle, 2001), psychologists (Carver \& Scheier, 1982; Mischel 1958; Mischel, Ebbesen, Zeiss, 1972; Muraven, \& Baumeister, 2000), neuroscientists (Brass \& Haggard, 2007; Heatherton \& Wagner, 2011; Tabibnia et al., 2011), and the general public (Druckerman, 2014; Tough 2009).

Regardless of whether a person's efforts at self-control succeed or fail, the act of exercising self-control can be phenomenologically aversive (e.g., Kurzban, 2016). Insofar as individuals strive to maintain a positive emotional state, one consequence of exercising selfcontrol may thus be a temporarily tuning toward or amplification of reward-related impulses 
(arising presumably to countermand the aversive feelings that stem from self-control). The current paper reviews theoretical and empirical evidence pertaining to the idea that exercising self-control increases reward responsivity, or the degree to which one experiences pleasure in the anticipation and presence of reward-related stimuli.

\section{The Reward System}

Rewards are incentives that shape learning, behavior, and goal pursuit. Primary rewards like food and sex directly promote survival via nourishment and opportunities to procreate, respectively (Haber \& Knutson, 2010), whereas secondary rewards like money indirectly promote survival through the procurement of food, shelter, social status, and other valuable resources. Both the wanting and liking of rewards have been linked to a fronto-striatal reward circuit in the brain, which includes the orbitofrontal cortex (OFC), ventromedial prefrontal cortex (vmPFC), and the nucleus accumbens (NAcc), among other regions (Haber \& Knutson, 2010). This reward circuit is activated by food (e.g., Berridge, 1996; Smith \& Robbins, 2013), sexual attraction (e.g., Cloutier, Heatherton, Whalen, \& Kelley, 2008), drugs (e.g., Wise, 2004), money (e.g., Balodis et al., 2012), and several other stimuli. ${ }^{1}$

But rewarding stimuli can trigger strong impulses (i.e., desires) that interfere with goaldirected behavior. For example, strong desires may contribute to drug addiction, personal debt, obesity, and other outcomes that carry both personal and societal costs. As a result, behaviors motivated by strong desires are frequently the targets of self-control attempts (Hofmann, Baumeister, Förster, \& Vohs, 2012). We propose that exercising self-control, like experiencing other taxing cognitive states like stress (e.g., Adam \& Epel, 2007) and sleep deprivation (e.g., Gujar, Yoo, Hu, \& Walker, 2011), amplifies the reward system.

\footnotetext{
${ }^{1}$ Journal impact factors activate aspects of this reward circuit in scientists (see Paulus, Rademacher, Schäfer, MüllerPinzler, \& Krach, 2015).
} 
Reward is a heterogeneous concept associated with many distinct neurocognitive processes. Concepts like reward responsivity, reward processing, and reward-seeking are interrelated but may, for different theorists, refer to different elements of the reward system. In the current paper, we use these terms somewhat interchangeably to refer to the degree or intensity of responding to reward-related stimuli, with the understanding that such responding broadly entails approach motivation for actions or stimuli that provide a sense of pleasure. We first review prominent perspectives on self-control focusing on how each theory construes the relationship between control and reward. Then we consider behavioral and neural evidence that exercising control potentiates reward responsivity and consider the implications for future research.

\section{Theoretical Accounts of Self-Control}

Resource Model of Self-Control. According to the resource model of self-control, the capacity to override or alter one's responses depends on a limited inner resource or strength (Baumeister, Bratslavsky, Muraven, \& Tice, 1998; Baumeister, Heatherton, \& Tice, 1994; Baumeister, Vohs, \& Tice, 2007). Acts of self-control are thought to consume or deplete this strength, resulting in a temporary decline in the capacity for self-control (i.e., ego depletion). In support of this viewpoint, numerous studies have found that engaging in a taxing (or depleting) self-control task temporarily undermines performance on subsequent demanding tasks (see Baumeister et al., 2007). Mechanistically, these effects are purported to be driven by glucose, with self-control success rising and falling in step with glucose levels in the bloodstream (Gailliot et al., 2007). However, empirical challenges, controversies, and debates related to the 
validity of the resource model have arisen. These challenges are not directly relevant to the current review, which focuses on aftereffects of self-control that involve reward processing. ${ }^{2}$

The resource model does not predict that exercising self-control increases subsequent reward-related impulse strength, but several studies inspired by the resource model have found evidence that exercising self-control increases subsequent reward seeking behavior, including eating, spending, and sexual behavior (see Baumeister et al., 2007). We briefly review this evidence below, noting that many of these behavioral outcomes could be due to a reduction in the capacity for control (as was initially assumed) or due to increases in reward responsivity and approach motivation (as we propose). We also review studies that circumvent this interpretational ambiguity by having participants' complete reward-related tasks requiring little to no self-control. These studies, which are less amenable to the typical resource depletion interpretation, were inspired by the process model of self-control.

Process Model of Self-Control. In addition to the empirical challenges mentioned above, theorists have also posed conceptual challenges to the resource model of self-control by questioning the validity and usefulness of the concept of limited resources. These challenges have resulted in alternative accounts of self-control that jettison the notion of resources in favor of other explanatory mechanisms. According to the process model (Inzlicht \& Schmeichel, 2012; Inzlicht, Schmeichel, \& Macrae, 2014), exercising self-control is an aversive activity that causes

\footnotetext{
${ }^{2}$ The resource model has enjoyed widespread influence in social and personality psychology and beyond, but recent evidence has challenged the validity of the model. An initial meta-analysis of the aftereffects of exercising selfcontrol found evidence for consistent, large effects (Hagger, Wood, Stiff, \& Chatzisarantis, 2010), but a more recent meta-analyses concluded that the effect does not differ from zero after adjusting for publication bias (Carter, Kofler, Forster, \& Mccullough, 2015; Carter \& McCullough, 2014). However, the validity of the bias correction techniques used by Carter and McCullough have been called into question (see Inzlicht, Gervais, \& Berkman, 2015; Moreno et al., 2009; Reed, 2015; Simonsohn, 2017), and although one multi-laboratory test of the resource model found a nonsignificant aftereffect of self-control exertion (Hagger et al., 2016), other preregistered, large-sample studies have found statistically significant (if smaller than expected) effects (Dang, Liu, Liu, \& Mao, 2017; Garrison, Finley, \& Schmeichel, in press).
} 
shifts in motivation and attention that combine to undermine subsequent attempts at self-control. Hence, rather than an inner resource or strength becoming depleted with use, in this view individuals become more attuned to rewards after they have expended effort to engage control. The process model thus explicitly suggests that shifts in attention and motivation tune individuals toward rewards and gratification. Similar to the notion of self-licensing - the tendency to prefer rewards (often indulgent ones) when they can be easily justified by difficult circumstances (e.g., stress, fatigue, see DeWitt Huberts, Evers, \& De Ridder, 2012; 2014; Prisen, Evers, Wijingaards, van Vliet, \& De Ridder, 2018) — the process model proposes that individuals may feel as though they deserve a reward for their prior exertions, so they seek more rewarding or relaxing events to help reduce the negative affect accompanying the exertion of control. These shifts in motivation and attention seem to bias individuals away from further engagement of control and toward rewards.

Integrative Self-Control Theory. Another theoretical model highlighting the role of rewards in self-control is Kotabe and Hofmann's (2015) integrative self-control theory (SCT). According to SCT, the need for control arises when desires come in to conflict with higher-order long-term goals. This desire-goal conflict signals the need to mobilize effortful control resources. Holding environmental factors constant, when the balance between these conflicting forces leans toward control (effort $>$ desire), the behavioral consequence is action in line with long-term goals. When the balance leans toward desire (effort $<$ desire), however, the behavioral consequence is acting on one's immediate desires. When equilibrium exists between the forces $($ effort $=$ desire $)$, SCT predicts an iterative process whereby one force eventually wins out. One interpretation inspired by this theory is that, because control efforts are taxing and dependent 
upon finite resources, exercising self-control (without any other intervening forces) may eventually tip the scales toward greater desire-driven reward seeking behavior.

Self-Control as Value-Based Choice. An additional theoretical model casts self-control as a value-based choice that entails a cost-benefit analysis of choice alternatives and results in the behavioral enactment of the most (relatively) valuable alternative (Berkman, Hutcherson, Livingston, Kahn, \& Inzlicht, 2017; Pfeifer \& Berkman, 2018). The subjective value of each choice alternative is computed as the sum total of the (weighted) value of the attributes of said choice alternatives. Attributes include tangible features (e.g., primary reward values, punishments, effort costs) as well as intangible social features (e.g., social status), and selfrelated intangible features (e.g., feelings of autonomy). Certain attributes may be weighted more heavily in subjective value calculations in a dynamic and iterative fashion, with subjective values being updated or revised with new information. According to this model, information continues to come in until an internal threshold for action is reached. This evidence accumulates in brain areas like ventromedial prefrontal cortex, which tracks subjective value (Clithero \& Rangel, 2014; Kable \& Glimcher, 2007; Strait, Blanchard, \& Hayden, 2014), and neurobiological computational modeling work has found that individual are likely to make an impulsive desiredriven (versus self-controlled) decision when the subjective value of that desire is high or the threshold for action is low, leading to a faster accumulation of evidence to cross the threshold for action (e.g., Hutcherson, Bushong, \& Rangel, 2015).

But how does exercising self-control influence subsequent decision-making from the perspective of the value-based choice model? One possibility is that exercising control shifts valued-based calculations in favor of more immediate, hedonic options over (more effortful) options in line with one's long-term goals. Consider an individual who has just completed a 
cognitively demanding task (e.g., tax preparation) prior to going out to dinner. At dinner, the cognitively taxed tax-preparer has a choice between two entrees: the healthy option (e.g., a salad) and an unhealthy option (e.g., a cheeseburger and fries). From the perspective of a subjectivevalue model, after exercising self-control the subjective value calculations may assign additional value to the rewarding attributes of the burger and minimize the costs of eating the burger, ultimately leading to a lower decision threshold for consuming the burger. We may also expect an opposite pattern of calculation for the salad, whereby the long-term rewarding attributes of eating the salad are minimized and the short-term costs are maximized.

Like the process model, the value-based choice model highlights the central role of motivation and attention in self-control. Specifically, it suggests that attentional processes represent a gating mechanism constraining the choices one makes. Moreover, the subjective calculations involved in choosing speak to the motivational shifts specified by the process model. Like Kotabe and Hofmann's (2015) integrative self-control theory, the value-based choice model incorporates an iterative component insofar as new information is integrated into ongoing and subsequent cost-benefit analyses. In summary, the value-based choice model provides a potential neurocognitive framework for thinking about how exerting self-control may increase reward responsivity - by shifting the weights attributed to the subjective value of seductive immediate rewards versus more logical long-term goal pursuits.

Self-Control is Aversive and Costly. Multiple theoretical perspectives are thus congruent with the possibility that the extended engagement of control systems may lead to stronger desires and reward seeking behavior. This shift may be due to the inherently aversive nature of self-control and other forms of mental effort (e.g., Dreisbach \& Fischer, 2015; Inzlicht, Bartholow, \& Hirsh, 2015; Inzlicht, Shanhav, \& Olivola, 2017; Kurzban, 2016; Saunders, Lin, 
Milyavskaya, \& Inzlicht, 2017). Indeed, tasks requiring effort are routinely experienced as aversive, and individuals show monetary discounting on cognitively effortful tasks by choosing to complete less effortful tasks for smaller rewards over more effortful tasks for larger rewards (Westbrook, Kester, \& Braver, 2013). Because mental effort is aversive, the opportunity cost of sustaining effort eventually becomes too high, and as a result limited cognitive resources are reallocated for other processes (see Kurzban, Duckworth, Kable, \& Myers, 2013). This reallocation of cognitive resources away from control may increase the likelihood of acting on desires or rewards.

Furthermore, both cognitive dissonance (e.g., Aronson \& Mills, 1959; Harmon-Jones \& Mills, 1999) and psychological contrast (e.g. Zentall, 2010) accounts of effort suggests that aversive states elicited by the exertion of effort make the end-result or reward appear more valuable, explaining why even non-human animals place higher values on rewards following high-effort tasks. Additionally, research on counter-regulation is consistent with the idea that exercising self-control may increase reward responsivity. According to this view, individuals more easily process information that is incongruent with their prevailing state (e.g., Rothermund, Voss, \& Wentura, 2008). Insofar as exercising self-control is aversive, perhaps especially when controlling an appetitive desire, a counter-regulation view would predict greater ease in processing reward-relevant information, leading to a compensatory attentional shift toward rewards after a bout of effortful control.

Opponent-Process Accounts. In addition to recent theoretical advances, support for the hypothesis that exercising self-control increases reward responsivity can also be found in older opponent-process theories of motivation (Solomon, 1980; Solomon \& Corbit, 1974). Opponentprocess theories assume that organisms have a fundamental motivation to maintain homeostasis, 
and shifts in affective states over time are thought to be a consequence of this motivation to maintain balance. Prolonged strong emotional states (state A) can have strong opposing emotional aftereffects (state B). For example, pain relief is well understood as an opponent process to pain (Leknes, Brooks, Wiech, \& Tracy, 2008). Countermanding aftereffects (state B) are slave processes, meaning that they are directly caused by the initial state (state A). An opponent-process perspective has implications for self-control insofar as immediate gratification (or reward seeking) is the opponent process for delaying gratification (or effort expenditure). Self-control exertion is aversive, so prolonged exertion may eventual trigger an internal threshold that temporarily shifts attention toward sources of reward or good feelings until homeostasis is attained. As this increase in reward responsivity is a slave process, we can infer from the view of opponent-process theory that exercising self-control causes increases in reward responsivity.

Theoretical Summary. Taken together, the theoretical accounts highlighted in this section construe self-control as costly and aversive. As a results, motivational and attention systems may selectively tune individuals towards sources of rewards to reduce or offset the aversive nature of effortful self-control. We consider both the aversive and appetitive facets of control to be crucial for understanding mental effort, both phenomenologically and mechanistically. In our view, reward-relevant aftereffects have been underappreciated in selfcontrol research, which has focused mainly on the aversive or depleting nature of control. Below, we review behavioral, function neuroimaging, and electroencephalographic (EEG) studies pertaining to reward-related processes after individuals exercise self-control.

\section{Behavioral Evidence}


A number of studies have observed behavioral evidence consistent with the hypotheses that exercising control subsequently increases reward responsivity. This pattern has been revealed in studies related to food consumption, drug and alcohol use, gambling and economic decision making, as well as in studies of positive affect and general reward processing. In addition to laboratory studies, conceptually similar results have been obtained in experience sampling studies of daily fluctuations in self-control and reward responsivity.

Food. As a primary reward for both humans and non-human animals, food promotes survival by providing the body with caloric fuel. Food desire and consumption thus represent suitable targets for testing reward-relevant aftereffects of self-control exertion. One popular approach has been to study dieters because they simultaneously desire both to eat delicious foods and to restrain food consumption to reach long-term weight and shape goals. From the perspective of Kotabe and Hofmann's (2015) integrative self-control theory, dieters have strong desire-goal conflict.

Vohs and Heatherton (2000) found that dieters who had previously resisted the temptation to consume delicious snacks and candies went on to eat more ice cream compared to non-dieters and dieters who were not tempted (Study 1). More recently, Hagger and colleagues (2013) found similar results using BMI rather than dieting status as the relevant individual difference variable, such that persons with higher BMI ate more cookies and candies after exerting self-control relative to their low BMI counterparts and relative to those who did not exert self-control. A more recent study by Haynes, Kemps, and Moffitt (2016) found that exercising self-control reduced the subsequent desire to control one's diet among weightconcerned women but did not affect food consumption. However, this study did not include a 
comparison condition of non-weight concerned women, making it hard to compare with the other studies described above.

Similar results have been obtained in studies of non-dieters as well. In one study, some participants exercised self-control and others did not. In a subsequent food tasting task, those who had exerted self-control reported a greater desire to eat cookies and consumed more cookies. Furthermore, greater desire strength mediated the relationship between self-control exertion and food consumption (Vohs, Baumeister, Mead, Ramanathan, \& Schmeichel, 2011, Study 3). Another study found that exerting self-control increased subsequent candy consumption compared to not exerting self-control, particularly among participants higher in trait self-control or restrained eating tendencies (Imhoff, Schmidt, \& Gerstenberg, 2013, Study 1). Similar results were obtained by Hoffman, Rauch and Gawronski (2007), who found that the effect of self-control exertion on subsequent candy consumption was moderated by implicit attitudes toward candy. Together, these studies point to the possibility that prior acts of selfcontrol increase sensitivity to food rewards, perhaps particularly for individuals high in foodrelated desire-goal conflict.

Drugs. Although the reward system evolved to respond to survival-promoting stimuli like sex and food, it is well documented that drugs of abuse, including both alcohol (e.g., Noble, 1996) and tobacco (e.g., Corrigall, Franklin, Coen, and Clarke, 1992), also recruit this same reward circuitry (e.g., Kelley \& Berridge, 2002). Drugs thus represent another avenue for examining reward sensitivity after self-control exertion.

In one study, male social drinkers exerted self-control (or not) and then sampled beer in a simulated bar setting (Muraven, Collins, \& Neinhaus, 2002). Participants who had exerted selfcontrol consumed more beer and had a higher blood alcohol concentration. Furthermore, the 
effect of self-control on alcohol consumption was moderated by desire strength - those who had the greatest desire to drink consumed the most after self-control exertion. Muraven and colleagues interpreted these results as evidence of a depleted capacity for control. However, the fact that these results were most pronounced among those high in alcohol desire strength suggests that the effect may be driven by increased reward responsivity rather than diminished control capacity. Similar results were obtained in another study of heavy social drinkers (Christiansen, Cole, \& Field, 2012). Additionally, one study observed aftereffects of self-control exertion on drinking among persons high in both approach and avoidance motivational tendencies (Schlauch, Christensen, Derrick, Crane, \& Collins, 2015). This finding suggests that both desires (i.e., high approach motivation) and conflict (i.e., high avoidance motivation) are important for understanding alcohol-related aftereffects of self-control exertion.

Exercising self-control may also cause cigarette smokers to smoke more (Shmueli \& Prochaska, 2009). Smokers either exerted self-control by resisting the temptation of a large plate of baked goods, or they did not exert self-control by sitting with a plate of vegetables. Participants then took a break before the next part of study, providing them an opportunity to smoke. When participants returned to the lab, expired air carbon monoxide $(\mathrm{CO})$ was measured to determine how much participants had smoked during the break. Participants who exercised self-control by resisting the baked goods in the first phase of the study had greater mean CO levels and were more likely to have smoked compared to participants who did not exert selfcontrol (i.e., those who resisted consuming vegetables). This effect was stronger for moderate to heavy smokers and for smokers who reported being more dependent on cigarettes, suggesting again that this effect was more pronounced among participants with a greater desire-goal 
conflict. Collectively, these studies suggest that exercising self-control increases drug use motivation and behavior particularly in the presence of strong desires.

Money and Other Resources. Unlike food and drugs, money represents a secondary reward through its ability to facilitate the procurement of primary rewards, making money another way to study the reward-related aftereffects of self-control. In a series of studies, Bruyneel, Dewitte, Franses, and Dekimpe (2009) explored how mood influence gambling behavior. They observed that negative affect was associated with increased gambling (Study 1), consistent with the idea that gambling may function to counter aversive feelings. In three subsequent studies, after self-control exertion participants bought more lottery tickets compared to participants who had not exerted self-control. These studies thus provided more direct evidence that exercising self-control increased reward-seeking behavior. Similar results were obtained by Schmeichel, Harmon-Jones, and Harmon-Jones (2010), who found that participants who had previously exerted self-control went on to bet more on a gambling task (Study 2b) and were better able to identify monetary cues $(\$)$ versus non-monetary cues $(\%)$ on a visual search task compared to participants who had not previously exercised self-control (Study 3).

In another series of studies, individuals who had previously exerted self-control were less likely to behave prosocially and instead selfishly accumulated more money and resources on economic resource allocation tasks (Osgood \& Muraven, 2015). Participants in a first study were randomly assigned to exert self-control (or not) before they completed an economic decisionmaking task knows as the centipede game (Rosenthal, 1981). In this game, participants were presented with two pools of money, with one pool being substantially larger $(\$ 0.50)$ than the other $(\$ 0.10)$. Their task was to choose to keep the larger pool of money, thereby giving the smaller pool to the other participant, or to pass the decision onto the other participant, who could 
then choose to keep the larger amount or pass again. Each pass asymmetrically increased the amount of money in each pool (by $\$ 0.50$ for the large pool and $\$ 0.10$ for the small pool), so the participants' decisions pitted their own self-interest (keeping more money for themselves) versus the greater good (increasing the pool of money available to others). In Osgood and Muraven's version of the game, participant always made the first choice and the fake computerized participant always passed. Those participants who had previously exerted self-control passed less during the centipede game compared to those who had not exerted self-control, suggesting that exerting control increased the desire to reward oneself (at the expense of others).

In a second study, participants played a different resource allocation game (i.e., a virtual fishing game) after exerting self-control (or not). On each turn, participants could take as many fish as they liked, but they also received a recommended number of fish to take on a trial-to-trial basis and were informed that after each round the fish population would decrease by $25 \%$. To increase performance motivation participants were led to believe that each fish caught would decrease the amount of time they would have to spend on a subsequent unpleasant task. Like Study 1, the results of Study 2 revealed that prior exertions of self-control caused participants to take more fish. These results are consistent with the idea that exercising self-control causes individuals to be more selfish in accumulating rewards or resources for themselves at the expense of others, suggesting an increase in reward responsivity.

Monetary reward-related aftereffects of self-control have also been studied using a dictator game to measure greediness versus selflessness. The dictator game is an economic decision-making game wherein one participant (the proposer) is in charge of distributing money between themselves and another participant (the responder). The responder is only able to accept or reject the proposer's offer. Participants in one study exerted self-control before they played 
the dictator game as the proposer (Achtziger, Alos-Ferrer, \& Wagner, 2015). Those who had exerted self-control in the first phase of the experiment kept more money for themselves throughout the task, thereby acting in a more self-serving manner. This pattern is consistent with the view that the hedonic value of money was more salient or appealing to those who had previously exerted self-control.

Impulsivity and Risk-Taking. One potential consequence of elevated reward responsivity is increased impulsivity and risk-taking (e.g., Braams, van Duijvenvoorde, Peper, \& Crone, 2015; Galavan, Hare, Voss, Glover, \& Casey, 2007; Steinberg 2010). A pair of studies found evidence that exercising self-control increases risk taking on measures of hypothetical decision making and behavioral risk-taking, respectively (Freeman \& Muraven, 2010). In Study 1, after exerting self-control or not, participants completed a modified version of the choice dilemmas questionnaire wherein participants read 12 vignettes pitting a desirable option with a low likelihood of attainment (i.e., the risky choice) against a less desirable alternative with a high likelihood of attainment (i.e., the safe choice) (adapted from Kogan \& Wallach, 1964). After exerting self-control, participants selected more risky choices on the choice dilemmas questionnaire. In Study 2, self-control exertion was manipulated before participants completed the Balloon Analogue Risk Task (BART; Lejuez et al., 2002), in which participants press a button to increase the size of a balloon on a computer screen. Participants earned more money the more times they pressed the button, but each press increased the likelihood of the balloon popping, resulting in no money. The number of button presses indexed risk taking. Participants who had exerted self-control (versus those who had not) went on to press the button more often on the BART, which belies a tendency toward risk-taking and reward-seeking. Other studies have similarly observed that self-control exertion increases subsequent sensation-seeking and 
risk tolerance (Fischer, Kastenmuller, \& Asal, 2012), although such findings have typically been interpreted as evidence for a reduction in self-control capacity as opposed to an increase in reward responsivity.

In addition to risk-taking, exerting self-control has also been found to influence delay of gratification. In one study, participants first exerted self-control (or not) before playing a computer game designed to assess delay of gratification behavior (Schmeichel \& Vohs, 2009, Study 4). The goal of the game was to accumulate as many points as possible. On each trial, participants had to choose either the shape that delivered a small number points quickly or the shape that delivered a large number points after a delay. Participants who had exerted selfcontrol in the first phase of the study earned fewer points (i.e., they were less able to delay gratification) compared to those who had not exerted self-control.

Collectively, the evidence reviewed in this section suggests that, following self-control exertion, individuals are more willing to take risks and less willing to wait to obtain rewards. Results pertaining to risk and delay preferences are important because they are relevant to risky sexual encounters, binge drinking, and other behaviors that can have long-lasting and in some cases life-changing consequences. The extent to which prior exertions of self-control influence these real-world outcomes remains to be seen, but the research reviewed in this section suggests the potential usefulness of research into reward responsivity outside the laboratory.

Positive Affect. In addition to studies of behavior in the context of primary and secondary rewards, which may confound the relevant contributions of reward responsivity and self-control capacity, several studies have also explored more general modulation of positive affectivity in tasks that do not require self-control. Positive affective events increase rewardrelated neural activity (e.g., Young \& Nusslock, 2016). If exercising self-control increases 
reward-related responding, then it may also increase emotional reactivity to positive or pleasant stimuli. Consistent with this view, a study by Schmeichel et al. (2010, Study 1) found increases in self-reported approach motivation (often related to positive affect) after participants had exerted self-control. The dependent measure in this study (i.e., self-reported approach motivation) was unrelated to self-control and not easily interpreted through the lens of decreased control capacity.

One accepted method for elucidating a process underlying an experimental effect is to examine the role of individual difference variables that influence the tendency to engage the proposed process (e.g., Gohm \& Clore, 2000; see also Underwood, 1975). Examining whether such individual differences moderate an experimental effect is a way to test assumptions about the processes or mechanism underlying the effect. Individual differences in approach motivation have been linked explicitly to variations in reward sensitivity (e.g., Beaver et al., 2006; Carver \& White, 1994), so trait approach motivation is a likely moderator of the aftereffects of self-control on reward responsivity. In two studies, Crowell, Kelley, and Schmeichel (2014) found that individual differences in reward responsivity moderated the affecteffects of self-control exertion. Specifically, following self-control exertion, those higher in trait approach motivation demonstrated increased optimism (Study 1) and a broadened attentional scope (Study 2) — two outcomes associated with approach motivation - compared to participants who did not exert selfcontrol. These results lend support to our central thesis, namely that shifts in motivational orientation toward increased reward sensitivity represent one process by which exercising selfcontrol influences subsequent responding.

More recently, a pair of studies by Finley and Schmeichel (2018) examined the extent to which prior self-control shifts emotional evaluation of affective stimuli. Participants first exerted 
self-control (or not) and then viewed positive, negative, and neutral images and reported their emotional reactions to the pictures. After self-control exertion, participants reported feeling more positive affect in response to positive images, and this increase was particularly prevalent among participants with a proneness toward positive affectivity (i.e., those higher in extraversion). A second (direct replication) study found increased valence to positive images after self-control exertion regardless of extraversion (c.f., Wiesner \& Lindner, 2017, who found more positive response to neutral but not positive images after self-control exertion). $\mathrm{T}$

Overall, it appears that exerting self-control may enhance subsequent positive emotional reactivity, perhaps especially among individuals prone to experiencing positive emotion. The studies reviewed in this subsection offer strong support for the reward responsivity hypothesis insofar as the positive affective responses did not call for or otherwise require self-control. As a result, these findings are more readily explained by an increase in reward responsivity as opposed to a decrease in self-control capacity.

Behavioral Summary. Consistent with the hypothesis that self-control exertion increases reward responsivity, a number of behavioral studies have observed that after exercising selfcontrol individuals act and report being more sensitivity to rewarding stimuli. This basic effect has been observed in studies of responding to food, money, drugs, and positive affective images. In the sections that follow, we highlight results from neuroscientific studies that suggest an increase in reward sensitivity following self-control exertion.

\section{Functional Neuroimaging Evidence}

Convergent evidence from social, cognitive, and affective neuroscience research reveals that the interplay between the prefrontal cortex and subcortical systems subserving threat and reward processing is crucial for self-regulation (for reviews, see Berkman, 2017; Heatherton \& 
Wagner, 2011; Kelley, Wagner, \& Heatherton, 2015; Wagner \& Heatherton, 2017). Numerous studies have found that successful self-control is associated with increased activity in the prefrontal cortex and a corresponding reduction in activity in subcortical regions involved in reward and threat processing (e.g., Dambacher et al., 2014; Giuliani, Mann, Tomiyama, \& Berkman, 2014; Lopez et al., 2017; Vijayakumar et al., 2014). By contrast, self-control failures are more likely to occur when top-down prefrontal control is diminished or when the balance in neural activity favors threat and reward systems (e.g., Chester \& DeWall, 2014; Demos, Heatherton, \& Kelley, 2012; Figner et al., 2010; Lopez, Hofmann, Wagner, Kelley, \& Heatherton, 2014; McClure et al. 2004 ; 2007; Meyer \& Bucci, 2016; Wagner, Altman, Boswell, Kelley, \& Heatherton, 2013; Wagner \& Heatherton, 2012).

Indirect support for the hypothesis that exercising self-control increases reward responsivity comes from research on individuals with addictions (e.g., smokers, Wilson, Sayette, \& Fiez, 2013), patient populations (e.g., multiple sclerosis patients; DeLuca, Genova, Hillary, \& Wylie, 2008; Finke et al., 2015), relevant individual differences (e.g., BMI; e.g., Petit et al., 2016; Rapuano, Huckins, Sargent, Heatherton, \& Kelley, 2016) and studies linking neural activity to behaviors in daily life (e.g., Lopez et al., 2014; Lopez, Milyavskaya, Hofmann, \& Heatherton, 2016). In brief, these studies converge on the conclusions that 1) the balance between cortical-subcortical activity plays a role in shaping self-control outcomes, and 2) repeated exposure to taxing situations (including dieting and chronic fatigue) increases activity in subcortical reward regions. These lines of research provide only indirect support for the hypothesis, so they are beyond the scope of this review. Below we focus on laboratory investigations of self-control exertion, but we also consider two conditions-dietary restraint and choice - that are directly relevant to self-control. Note that in the studies reviewed below, 
reward-related aftereffects were generally conceptualized as activation (i.e., blood oxygenation level dependent [BOLD] signal) in regions in the fronto-striatal reward circuit or as the balance in activity between this circuit and frontal control regions.

Laboratory Self-Control Exertion and Reward-Related Neural Activity. Wagner, and colleagues (2013) conducted an fMRI study to examine changes in neural responses to food cues in chronic female dieters. Participants completed an attention control task in the scanner. Then they completed a food-cue reactivity task that involved viewing images of food interspersed among other images in an incidental judgement task (i.e., indicating whether an image was an indoor or outdoor scene). After self-control exertion, participants exhibited greater neural activity in response to food images in two reward-relevant regions, the OFC and the ventral striatum. Further, participants who had previously exerted self-control showed reduced functional connectivity between the OFC and the inferior frontal gyrus (IFG), a region implicated in cognitive control. Among those who had previously exerted self-control, greater reports of exertion (quantified as a composite of fatigue and task difficulty) were associated with greater food image reactivity in the OFC. No such association was observed among those who had not exerted self-control. Consistent with the thesis of the current paper, Wagner and colleagues thus found that prior self-control alters subsequent neural processing of rewards as revealed in exaggerated responses to food images in OFC and similar (but non-significant) patterns in ventral striatum. As the image-viewing task used in this study did not require selfcontrol, the results are more in line with the increased reward responsivity hypothesis than with a resource depletion view of the aftereffects of self-control.

As discussed previously, dieters are an ideal group in whom to study the aftereffects of self-control because they (typically) desire both to eat delicious foods and to achieve long-term 
weight and fitness goals. This strong desire-goal conflict is cognitively taxing and thus may lead to enhanced reward-related aftereffects. One study observed that dieters who had violated their diets (by consuming a milkshake) subsequently showed enhanced activity in the ventral striatum while viewing images of delicious foods (Demos, Kelley, \& Heatherton, 2011). Consistent with motivational accounts of self-control failure (e.g., Inzlicht \& Schmeichel, 2012), these results suggest that once breaking one's diet tips the scales in desire-goal conflict to lean toward enhanced engagement with desires.

Another fMRI study using a different dependent measure yielded null findings. Leuthi and colleagues (2016) examined changes in neural responses after self-control exertion (or not) on a subsequent Stroop task incentivized with money (or not). Participants were randomly assigned to one of four conditions: depletion/high motivation, depletion/regular motivation, no depletion/high motivation, and no depletion/regular motivation. The results indicated that, in the absence of a financial incentive (i.e., regular motivation), prior self-control exertion impaired Stroop performance. But a financial incentive for performance (i.e., high motivation) eliminated the depletion effect on Stroop performance, consistent with evidence that financial incentives can counteract the effects of prior self-control exertion (Muraven, Shmueli, \& Burkley, 2006). Likewise, in the absence of a financial incentive, prior self-control exertion decreased activity in neural regions associated with cognitive control (e.g., the IFG), but this pattern was not observed when a financial incentive for performance was available. Not surprisingly, participants offered a financial incentive exhibited elevated nucleus accumbens activity irrespective of prior exertion. Based on the hypothesis that exertion increases reward reactivity, we would have predicted that activity in the nucleus accumbens would be boosted among those who had previously exerted self-control. Although the pattern of means was consistent with this hypothesis, the predicted 
differences were not statistically significant. However, the design of this study differs from the prior research in ways that may have contributed to the null findings, including the fast pace of the trials and knowledge of an unspecified financial reward for good performance to be delivered at the end of the task. In any event, past fMRI evidence provides mixed support from startlingly few studies for the hypothesis that self-control exertion enhances reward responsivity as assessed with neural measures.

One possible explanation for the mixed evidence is that completing effortful tasks for money after self-control exertion undercuts or dampens reward responsivity as compared to having free or effortless access to rewards or reward-related stimuli, as was the case in many of the behavioral studies reviewed above. In other words, the rewards in the study by Leuthi and colleagues (2016; i.e., unspecified amounts of money for good performance) may have been less rewarding than the rewards used in other studies (e.g., access to tasty snacks regardless of performance). Another potential explanation concerns more nuanced relationships among different types of rewards and different nodes on the reward network. More specifically, a metaanalysis of neural responses to three different types of rewards - money, food, and erotica found that all three rewards recruit activity in the vmPFC, striatum, amygdala, anterior insula, and thalamus. However, more abstract monetary rewards appeared to more strongly recruit the anterior OFC, whereas food and erotica more strongly recruited subcortical regions (Sescousse, Caldú, Segura, \& Dreher, 2013). The brain imaging studies reviewed above used images of rewards - abstract representations of actual rewards that may elicit more activity in more anterior portions of the OFC. Although some of the studies reviewed above did find evidence of greater reactivity in the OFC, perhaps subdividing the OFC to focus on more anterior portions would yield clearer support for the hypothesis that prior exertion increases reward responsivity. 
Although the results reported by Leuthi and colleagues (2016) did not provide clear support for the reward responsivity hypothesis, some elements of their findings are suggestive of such a view. As discussed above, self-control failures occur when top-down prefrontal control is diminished or when the balance in neural activity favors threat and reward. Consistent with this idea, Leuthi and colleagues found that when financial incentives were not present (the normal motivation condition), those who exerted self-control (versus not) showed a decrease in activity in cognitive control regions (e.g., the IFG) and a slight (albeit non-significant) increase in reward regions (e.g., nucleus accumbens). Thus, after self-control exertion the combination of decreased control-related activity and increased reward-related activity suggests a tipping of the scales toward rewards. However, with a financial incentive present, participants showed no differences in neural activity in cognitive control regions or reward regions as a function of prior self-control exertion. Although this way of interpreting the results is more consistent with the hypothesis, continued research in this area is sorely needed.

Choice. Many of the theoretical perspectives reviewed above pointed to the role of choice in self-control dilemmas (e.g., Berkman et al., 2017). Value-based choices, including conscious choices between options in a sea of alternatives, can be particularly effortful because they require a deeper level of processing and recruitment of cognitive resources. Across 5 studies, Vohs and colleagues (2008) found that making choices undermines behavioral indices of subsequent self-control. That is, making choices may induce a state of ego depletion. This behavioral work on choice is relevant because recent function imaging research has begun to examine how choice impacts reward processing in self-regulatory contexts. A study by Cosme, Mobasser, Zeithamova, Berkman, and Pfeifer (2018) asked participants to regulate their response to personally craved foods. Participants were instructed to reappraise their emotional responses 
to craved foods (the no choice condition) or were given the option to reappraise or not (the choice condition). Consistent with the behavioral work cited above, choice undermined selfcontrol in terms of emotion regulation success. At the neural level, choice impaired the ability to distinguish between look and emotion regulation instructions as revealed by multi-voxel pattern analysis of classification accuracy. These results suggest that one pathway whereby self-control exertion leads to increased reward responsivity (i.e., craving) is by temporarily disrupting the ability to distinguish between choices signaling desire (i.e., look) and choices signaling control (i.e., regulate).

Functional Imaging: Summary, Limitations, and Future Directions. In contrast to the research reviewed in previous sections, which provided robust theoretical and behavioral evidence for reward-related aftereffects of self-control, the functional imaging results reviewed here are somewhat limited. Only two studies directly explored reward-related aftereffects using a sequential task paradigm. One found that self-control exertion increased neural responses to food images in the OFC and ventral striatum (Wagner et al., 2013), and the other did not observe an effect of self-control exertion on reward-related neural activity during a task that promised monetary reward (Leuthi et al., 2016). Thus, fMRI studies have not provided conclusive support for the hypothesis that self-control exertion modulates subsequent reward-related neural activity.

In addition to exploring reward-related aftereffects of exerting self-control, other neuroimaging studies have explored more general increases in emotional reactivity following self-control exertion. For example, exercising self-control has been found to increase subsequent amygdala activation to negative images (Wagner \& Heatherton, 2012). This finding suggests that, in addition to increasing reward responsivity, prior self-control exertion may also increase 
threat responsivity. Future research is needed to more precisely map the affective aftereffects of self-control.

One key limitation hindering the precise mapping of reward-related aftereffects of selfcontrol in function imaging work is sample size. The studies reviewed above ranged from 33-100 participants. The two studies with the largest sample sizes, specifically Demos et al. $(2011 ; N=$ 100) and Luethi et al. $(2016 ; N=88)$ both used $2 \times 2$ between-subjects designs, resulting in roughly 20 to 25 participants per condition. Further, the study by Wagner and colleagues (2013) included 33 participants in a two-cell between-subjects design, leading to $N$ s per cell well under 20. Furthermore, Wagner and Heatherton's (2012) study of amygdala effects had 48 participants (24 per cell). Collectively, these studies likely had relatively low statistical power, potentially obscuring true effects or producing spurious ones. High -powered fMRI experiments of rewarding and emotional effects of self-control will provide more reliable effect size estimates and help researchers better understand the motivational consequences of self-control.

A second limitation of fMRI studies of self-control is a reliance on region of interest approaches despite the importance of frontal-striatal functional connectivity to self-controlled behavior (e.g., Jimura, Chushak, \& Braver, 2013). Of the imaging studies reviewed here only Wagner and colleagues (2013) examined functional connectivity. They found that participants who had previously exerted self-control showed reduced functional connectivity between the OFC and the inferior frontal gyrus (IFG). To date no studies have examined fronto-striatal functional connectivity after self-control exertion. One study found that when participants made choices favoring long-term goals over immediate desires, these choices were associated with a negative functional coupling between the PFC and striatal regions (Diekhof \& Gruber, 2010). This result points to the importance of fronto-striatal connectivity to self-controlled decisions. 
But does fronto-striatal connectivity change after exercising self-control? Insofar as exercising self-control increases reward responsivity, one possibility is that elevated striatal activity would be paired with decreased prefrontal activity (i.e., negative functional connectivity). This hypothesis has yet to be tested.

Whereas fMRI has excellent spatial resolution, it suffers from relatively poor temporal resolution due to the nature of the BOLD response (Belliveau et al., 1991; Hämäläinen et al., 1993; Kwong et al., 1992). As a result, fMRI may conflate brain activity associated with temporally proximate yet psychologically distinct processes; otherwise distinct reward-related neurocognitive processes that occur in close temporal proximity may be obscured by fMRI and may be better investigated using EEG, which has superior temporal resolution (Cohen, 2011). In the section that follows, we review studies that have used EEG to examine reward-related aftereffects of self-control. By harnessing the superior temporal resolution of EEG, these studies give additional insight into discrete neurocognitive aspects of reward processing impacted by self-control exertion.

\section{Electrophysiological Evidence}

EEG techniques have excellent temporal resolution (on the order of milliseconds) because they rely on electrical activity recorded at the scalp. The electrical activity derived from EEG is ideal for decomposing the time course of neural activation and is typically measured in the form of event-related potentials (ERPs) and time frequency bands. ERPs are fluctuations in the EEG signal that are synchronized to some aspect of an event (e.g., picture presentation, participant's response), averaged over many trials, and defined by their polarity, latency, and scalp location (see Luck, 2014). Time-frequency EEG activity is oscillatory activity during task engagement or at rest, defined across scalp location and five frequency bands: delta $(1-3 \mathrm{~Hz})$, 
theta $(4-7 \mathrm{~Hz})$, alpha $(8-12 \mathrm{~Hz})$, beta $(13-30 \mathrm{~Hz})$, and gamma $(30+\mathrm{Hz})$. In the sections that follow, we review research harnessing the temporal resolution of EEG to explore the neurocognitive processes involved in self-control exertion. We view this work as complementary to the fMRI work reviewed above.

Most prior ERP work has focused on the attentional consequences of fatigue or selfcontrol exertion. For example, after suppressing their emotions, participants have been found to show a reduced error related negativity $(\mathrm{ERN})$, a neurophysiological index of conflict monitoring (Inzlicht \& Gutsell, 2007; Wang, Yang, \& Wang, 2014). Additionally, after exerting self-control participants have been found to exhibit reduced attentional engagement with visual stimuli as measured by ERPs during a passive image viewing task (Garrison, Crowell, Finley, \& Schmeichel, 2017). Below, we review studies specifically examining reward-related aftereffects of self-control; these have focused primarily on the feedback related negativity (FRN) and alpha asymmetry.

The Feedback-related Negativity (FRN). The FRN (also known as the reward positivity) is the most frequently studied ERP in the context of reward and is the earliest ERP component (200-300ms after stimulus onset) dissociating gain from loss feedback (Glazer, Kelley, Pornpattananangkul, Mittal, \& Nusslock, 2018). Studies using simultaneous EEG-fMRI methods have linked FRN amplitudes to striatal activity (Becker, Nitsch, Miltner, \& Straube, 2014). It has been the most extensively studied reward-related ERP following the exertion of self-control. In one study, the FRN was examined after participants had engaged cognitive effort or not (Schmidt et al., 2017). More specifically, after completing a cognitively taxing Stroop task, participants exhibited a larger FRN during a subsequent gambling task relative to those who had completed an innocuous non-self-control task. The effect of prior self-control on FRN 
amplitude was most pronounced after wins, consistent with the idea that prior exertion of selfcontrol increases early neural responses to rewards.

Another study examined ERPs to rewards cues (versus no-reward cues) after participants completed a task requiring high or low effort (Ma, Meng, Wang, \& Shen, 2014). High effort trials required participants to multiply two 2-digit numbers, whereas low effort trials had participants add two 2-digit numbers. The results revealed that high effort trials (versus low effort trials) caused a larger discrepancy between the FRN to reward versus no-reward trials. High effort trials also increased the salience of rewarding feedback as reflected by the feedbackrelated P300. More recently, an EEG study by Milyavskaya, Inzlicht, Johnson, and Larson (2017) examined neural responses to rewards after cognitive effort (math problems), boredom (passively viewing numbers), or a control condition (no task). Irrespective of reward type (money or food), the boredom condition enhanced FRN magnitudes. Contrary to our prediction, the effort exertion condition did not enhance subsequent FRN magnitudes (although FRN magnitudes after effort did not differ from FRN magnitudes after boredom). Collectively, these studies provide some support for the idea that the FRN is modulated by prior self-control exertion, such that engaging control seems to increase subsequent reward-related processing.

Alpha Power. Alpha power is frequently studied in the context of lateralized patterns of activity in the frontal cortex, whereby left lateralized alpha activity is associated with approach motivation and reward sensitivity, whereas right lateralized activity is associated with avoidance motivation and threat sensitivity (e.g., Harmon-Jones \& Gable, 2018; Kelley, Hortensius, Schutter, \& Harmon-Jones, 2017). One study examined frontal asymmetry after self-control exertion. In this study, participants exerted self-control (or not) before viewing positive, neutral, and negative emotional images (Schmeichel, Crowell, \& Harmon-Jones, 2015). The results 
revealed that exercising self-control on the initial task increased left frontal alpha asymmetry to emotional images on the subsequent image viewing task, but only among individuals higher in trait approach motivation. Unlike many studies inspired by the resource model of self-control, the second task in this study (picture viewing) did not require self-control. These results are thus difficult to reconcile with a resource depletion perspective and more parsimoniously accounted for by an increase in reward responsivity.

Moreover, on the individual differences level, greater left lateralized frontal alpha activity has been associated with a greater willingness to expend effort to procure monetary rewards (Hughes, Yates, Morton, \& Smilie, 2015). As noted above, moderation of an experimental effect by individual differences is one accepted method for elucidating an underlying process (e.g., Gohm \& Clore, 2000; see also Underwood, 1975). By finding that effort expenditure is moderated by alpha asymmetry, the results of the study by Hughes and colleagues suggest that approach motivation (which is strongly related to reward responsivity) is a process underlying effort expenditure to procure rewards.

Summary, Limitations, and Future Directions. The greatest strength of EEG is its temporal resolution. Both ERPs and time-frequency data can be used to study discrete neurocognitive processes during the anticipation and appreciation of rewards. Processes like cue evaluation, motor preparation, outcome anticipation, and reward learning can all be obtained from a relatively small amount of EEG data. However, much of the work above neglected EEG's greatest strength by looking at only one ERP or time-frequency band. Further, ERPs other than the FRN and the P300 and time frequency bands other than alpha have been largely ignored. With regard to ERPs, previous work has almost exclusively focused on the FRN, which taps into early reward evaluation processes. A focus on outcome-related ERPs like the FRN allows 
researchers to ask how self-control exertion influences responses to obtained rewards. However, it does not allow researchers to consider how self-control exertion influences attentional processes subserving reward seeking. Future studies should consider how self-control exertion influences reward anticipation ERPs as well. For example, cue evaluation (indexed by the N200 and P300), motor preparation (indexed by the readiness potential or contingent negative variation), and feedback anticipation (indexed by the stimulus-preceding negativity, SPN) are all modulated in the context of reward (Glazer et al., 2018; Kelley, Glazer, Pornpattananangkul, \& Nusslock, 2019; Pornpattananangkul \& Nusslock, 2015) and may thus be influenced by prior self-control.

With regard to time-frequency data, beta activity has yet to be studied as an aftereffect of self-control. Beta activity is frequently studied in the context of motor preparation (Pfurtscheller et al., 1996; Sanes \& Donoghue 1993). Recent research has suggested that reduced beta activity over the motor cortex may reflect the propensity toward greater approach-motivated motor readiness (Threadgill \& Gable, 2018a). To date, no studies have explored how effort expenditure or self-control exertion influences subsequent beta activity. To the extent that self-control exertion sensitizes individuals toward rewards, it seems plausible that exertion would also influence the readiness of the motor system to seize rewarding stimuli.

In summary, EEG allows researchers to interrogate the temporal dynamics of reward processing. With such an approach, studies can more precisely investigate which neurocognitive processes are most (and least) impacted by self-control exertion. Future research is needed to examine these issues in more detail. We now turn to a final set of indirect evidence from the neuroscience of aggression before considering the implications of this review regarding the nature of self-control and promising future directions. 


\section{Indirect Support from the Neuroscience of Aggression}

Additional indirect support for reward-related aftereffects of self-control comes from research on aggression. Aggressive behaviors are actions undertaken with the intention of inflicting unwanted harm on a target. There is fairly robust empirical and theoretical evidence that exercising self-control on unrelated tasks increased subsequent aggression (for a review see Denson, DeWall, and Finkel, 2012). For example, a number of studies have found that participants behave more aggressively toward a transgressor after unrelated self-control exertions (Denson, von Hippel, Kemp, \& Teo, 2010; DeWall, Baumeister, Stillman, \& Gailliot, 2007; Stucke \& Baumesiter, 2006). Insofar as anger and aggression stem from approach-motivated impulses (see Carver \& Harmon-Jones, 2009), such evidence is broadly consistent with the reward responsivity hypothesis.

The idea that aggressive behavior may be associated with reward processing received additional support in a recent fMRI study. Chester and DeWall (2015) asked participants to engage in the Taylor Aggression Paradigm during a functional imaging session. They observed greater nucleus accumbens activity following retaliatory aggression (i.e., aversive noise blasts delivered following an aversive noise blast to the participant) compared to unprovoked aggression (i.e., aversive noise blasts delivered following an innocuous noise blast to the participant), suggesting that aggressive behaviors after provocation were rewarding.

Additional support for the aggression-reward link comes from electroencephalographic studies of the FRN. Trait anger (Angus, Kemkes, Schutter, and Harmon-Jones, 2015), state anger (Angus \& Harmon-Jones, 2018), and retaliatory aggression (Threadgill \& Gable, 2018b) have all been found to enhance the FRN. These results are consistent with Chester and DeWall's (2015) fMRI work insofar as the FRN is driven in part by striatal activity (Becker et al., 2014). 
Collectively, these results provide converging evidence across spatially and temporally precise neuroimaging techniques that retaliatory aggression may be rewarding, and thus lend some support to the view that elevated aggression after self-control exertion may be due in part to enhanced reward reactivity. Rather than relying on indirect evidence, however, future studies should examine the extent to which reward-related neural activity mediates the aftereffects of self-control exertion on aggressive behavior.

\section{Summary}

The brain's reward circuitry is activated by food, sex, drugs, and money, among other appetitive stimuli. These stimuli both trigger strong desires and are frequently the targets of control attempts. The interaction between desire and reward-seeking on the one hand and the exercise of self-control on the other hints that control and reward processing may be reciprocally related. Indeed, exercising control may help to forestall or temporarily inhibit desires, and the research reviewed here suggests an unintended and perhaps underappreciated consequence - an increase in subsequent reward responsivity after exertions of self-control, including toward potentially rewarding stimuli unrelated to the initial self-control attempt.

Several theoretical models of self-control converge on the importance of the relationship between control systems and reward systems. We reviewed behavioral studies highlighting the effects of exercising self-control on subsequent reactivity to food, money, drugs, and positive affect in both in daily life as well as inside the laboratory. Our review of neural findings from fMRI and EEG research revealed somewhat more mixed evidence for the hypothesis and highlighted the need for future research harnessing the strengths of each method to more precisely integrate how, when, and under what circumstances self-control exertion influences reward processing. 


\section{Implications for Theories of Self-Control}

Like opponent-process theorists (Solomon, 1980; Solomon \& Corbit, 1974), we view bouts of self-control as potentially aversive disruptions of motivational homeostasis. Like Kotabe and Hofmann (2015), we view the conflict between desires and goals to be a central feature of self-control dilemmas. And like Berkman and colleagues (2017) we believe that self-control entails choice. Further, like Inzlicht and Schmeichel (2012) we view shifts in motivation and attention as central to the aftereffects of self-control. The collective wisdom of these theories suggests a reward responsivity hypothesis of the aftereffects of self-control, whereby in an effort to return to a homeostatic baseline after initial bouts of self-control, attentional and motivational processes work in concert to constrain how choice alternatives are weighed during subsequent tasks. The consequence is a shift in the value of the choice alternatives and decision thresholds in favor of action toward immediate rewards (see Figure 1).

The research we have reviewed has implications for the resource model of self-control, which has come under intense scrutiny and debate in recent years (see Friese, Loschelder, Gieseler, Frankenbach, \& Inzlicht, 2018). Some researchers have suggested that the effects predicted by the resource model are smaller than once anticipated (e.g., Garrison, Finley, \& Schmeichel, 2018), whereas others have suggested that these effects are negligible at best (Carter et al., 2015; Hagger et al., 2016). By contrast, Baumeister and colleagues have reaffirmed their commitment to the resource model (Baumeister, Tice, \& Vohs, 2018; Baumeister \& Vohs, 2016). We think the perspective advanced in this paper may help to resolve these disagreements.

The original conceptualization of the resource model predicted that exercising selfcontrol at Time 1 undermines the ability to exercise self-control at Time 2 , resulting in a decrement in performance on challenging tasks irrespective of task type. In other words, 
according to the resource model, a domain-general but limited and depletable resource underlies all types of self-control (Baumeister et al., 1998; Muraven \& Baumeister, 2000). We contend that the aftereffects of self-control may influence reward-related processes rather than self-control per se.

Specifically, based on the theory and research reviewed here, we propose that rewardrelevant behavior and physiology should be especially affected following initial exertion of selfcontrol. In many instances, this change would manifest as poorer self-control, even though reward processing, not self-control capacity, is the relevant mechanism. We would also predict that threat-relevant and non-affective domains are less affected by prior self-control exertion. Whereas past research has suggested that the type of self-control exertion at Time 1 (e.g., suppressing positive emotional reactions, Fischer, Greitemeyer, \& Frey, 2007; 2008; suppressing negative emotional reactions, Inzlicht \& Gutsell, 2007; Schmeichel, 2007; or controlling blends of both positive and negative emotions, Friese, Hofmann, \& Wanke, 2008; Hofmann et al., 2007) does not moderate the aftereffects of exertion at Time 2, empirical and meta-analytic work have yet to systematically evaluate whether the aftereffects of self-control vary as a function of reward, threat, or non-affective context at Time 2. Additional research distinguishing among the types of processing required at Time 2 is therefore needed to refine evidence for the reward responsivity hypothesis.

Furthermore, as discussed previously, reward-relevant aftereffects are present in the existing literature on the resource model yet have been interpreted as decrements in control capacity. That is because research inspired by the resource model has typically used sequential task paradigms wherein participants complete two tasks requiring self-control in short succession, and the second task is often a behavioral outcome that may be shaped by reward 
processes, control processes, or both types of processes. Thus, even if reward responsivity is elevated on the second task, it may be interpreted as a decrease in control capacity. To investigate reward-relevant aftereffects more precisely, researchers using a sequential task paradigm should examine reward-relevant tasks that do not require self-control exertion at Time 2. By using tasks that disassociate reward processes and self-control, interpretations based on a decrease in the capacity for control can be ruled out.

There are a number of reasons to expect that effort or self-control exertion should amplify the reward system. First, as we have assumed throughout the course of this review, exerting control is aversive, so individuals may show subsequent biases toward reward responsivity in cognition, emotion, and behavior as a means to improve their emotional state. This is essentially an emotion regulation view of the aftereffects of self-control. Second, well-established cultural forces link effort expenditure to reward. For example, belief in the Protestant work ethic (Weber, 1958; Furnham, 1984), which seems to permeate many cultures (e.g., Furnham, 1993), is predicated on the notion that rewards are the byproduct of hard work. Hence, individuals may carry in their minds associations leading them to expect rewards in exchange for the expenditure of effort. In this view, expending effort potentiates one to expect a reward, and this may manifest as an increase in reward responsivity.

To the extent that cultures vary in their endorsement of the Protestant work ethic, research comparing reward-related aftereffects of self-control in cultures with a strong versus weak Protestant work ethic beliefs may shed light on the role of cultural dynamics in the reward responsivity effect. Moreover, the effort-reward association may be reinforced throughout development as children experience first-hand the benefits or rewards that accrue upon working hard. Indeed, the repeated exposure to reward-related aftereffects of effort exertion in humans 
and other animals is thought to contribute to learned industriousness, or individual differences in the propensity to allocate effort to demanding tasks (Eisenberger, 1992). Studies comparing reward-related aftereffects of self-control in children, adolescents, and adults may thus help to elucidate the idea that effort-reward associations develop with age. The emotion regulation view and the cultural learning account of the reward-related aftereffects of self-control are not mutually exclusive and likely represent an intertwined set of circumstances that both contribute to amplification of the reward system after bouts of self-control.

Finally, some theorists have speculated that executive functions (including working memory operations, behavioral inhibition, and task-switching) underlie successful self-control and that temporary reductions in executive function may help to explain many of the situational factors that reduce self-control (e.g., Hofmann, Schmeichel, \& Baddeley, 2012).It may be that cognitive abilities also play a role in the reward-seeking aftereffects of exercising self-control. Indeed, higher working memory capacity and intelligence have been found to relate to smaller delay discounting in intertemporal choice paradigms, whereby higher-capacity individuals wait longer for larger rewards (Shamosh \& Gray 2008). Moreover, lateral prefrontal mechanisms associated with working memory are enhanced in individuals preferring larger-but-later rewards in intertemporal choices (Shamosh et al. 2008; Jimura, Chushak, Westbrook, \& Braver, 2018). However, intertemporal choice paradigms also suffer from the interpretational ambiguity surrounding much self-control research, insofar as it is unclear if self-control failure in any particular instance is due to an increase in reward sensitivity or a reduction in the capacity for control. In regards to the impact of executive functioning on shifts in reward sensitivity, we see at least two possibilities. One, individual differences in executive functions may moderate the aftereffects of self-control such that high capacity individuals show less reward responsivity after 
exercising self-control, because self-control is easier or less aversive for them, and two, exercising self-control may temporarily compromise or reduce executive functions, which in turn may help to account for increases in reward responsivity. Such effects are likely to be driven in part by lateral prefrontal activity. We are aware of no prior research testing these hypotheses but they make for promising avenues for future research.

\section{Conclusion}

Self-control is crucial for goal-directed behavior and contributes to many consequential outcomes in life. Exercising self-control seems to temporarily amplify the reward system. Chronic exertion of self-control may lead to a dysregulated reward system and thereby contribute to outcomes that carry grave costs for individuals and societies, including alcohol and drug addiction, personal debt, obesity, and other undesirable outcomes. We hope this review will persuade researchers to conduct cross-sectional and longitudinal examinations of the rewardrelevant aftereffects of self-control, as well as high-powered investigations of the reward sensitivity hypothesis using neuroimaging and electrophysiological techniques. 


\section{References}

Achtziger, A., Alós-Ferrer, C., \& Wagner, A. K. (2015). Money, depletion, and prosociality in the dictator game. Journal of Neuroscience, Psychology, and Economics, 8, 1-14.

Adam, T. C., \& Epel, E. S. (2007). Stress, eating and the reward system. Physiology \& Behavior, 91, 449-458.

Addessi, E., Paglieri, F., \& Focaroli, V. (2011). The ecological rationality of delay tolerance: Insights from capuchin monkeys. Cognition, 119, 142-147.

Amici, F., Aureli, F., \& Call, J. (2008). Fission-fusion dynamics, behavioral flexibility, and inhibitory control in primates. Current Biology, 18, 1415-1419.

Angus, D.J. \& Harmon-Jones, E. (2018). The Anger Incentive Delay Task: A Novel Method for Studying Anger in Neuroscience Research. Manuscript submitted for publication.

Angus, D. J., Kemkes, K., Schutter, D. J., \& Harmon-Jones, E. (2015). Anger is associated with reward-related electrocortical activity: Evidence from the reward positivity. Psychophysiology, 52, 1271-1280.

Aronson, E., \& Mills, J. (1959). The effect of severity of initiation on liking for a group. The Journal of Abnormal and Social Psychology, 59, 177-181.

Balodis, I. M., Kober, H., Worhunsky, P. D., Stevens, M. C., Pearlson, G. D., \& Potenza, M. N. (2012). Diminished frontostriatal activity during processing of monetary rewards and losses in pathological gambling. Biological Psychiatry, 71, 749-757.

Baumeister, R. F., Bratslavsky, E., Muraven, M., \& Tice, D. M. (1998). Ego depletion: Is the active self a limited resource?. Journal of Personality and Social Psychology, 74, 12521265. 
Baumeister, R. F., Heatherton, T. F., \& Tice, D. M. (1994). Losing control: How and why people fail at self-regulation. San Diego, CA: Academic Press.

Baumeister, R. F., Tice, D. M., \& Vohs, K. D. (2018). The strength model of self-regulation:

Conclusions from the second decade of willpower research. Perspectives on Psychological Science, 13(2), 141-145.

Baumeister, R. F., \& Vohs, K. D. (2016). Misguided effort with elusive implications. Perspectives on Psychological Science, 11, 574-575.

Baumeister, R. F., Vohs, K. D., \& Tice, D. M. (2007). The strength model of selfcontrol. Current Directions in Psychological Science, 16, 351-355.

Beaver, J. D., Lawrence, A. D., van Ditzhuijzen, J., Davis, M. H., Woods, A., \& Calder, A. J. (2006). Individual differences in reward drive predict neural responses to images of food. Journal of Neuroscience, 26, 5160-5166.

Belliveau, J.W., Kennedy, D.N., McKinstry, R.C., Buchbinder, B.R., Weisskoff, R., Cohen, M.S., ... Rosen, B.R., 1991. Functional mapping of the human visual cortex by magnetic resonance imaging. Science 254 (5032), 716-719.

Becker, M. P., Nitsch, A. M., Miltner, W. H., \& Straube, T. (2014). A single-trial estimation of the feedback-related negativity and its relation to BOLD responses in a time-estimation task. Journal of Neuroscience, 34, 3005-3012.

Berkman, E. T. (2017). The neuroscience of self-control. In D. de Ridder, M. Adriaanse, \& K. Fujita (Eds.), Handbook of Self-Control in Health.

Berkman, E. T., Hutcherson, C. A., Livingston, J. L., Kahn, L. E., \& Inzlicht, M. (2017). Selfcontrol as value-based choice. Current Directions in Psychological Science, 26, 422-428. 
Berridge, K. C. (1996). Food reward: brain substrates of wanting and liking. Neuroscience \& Biobehavioral Reviews, 20, 1-25

Braams, B. R., van Duijvenvoorde, A. C., Peper, J. S., \& Crone, E. A. (2015). Longitudinal changes in adolescent risk-taking: a comprehensive study of neural responses to rewards, pubertal development, and risk-taking behavior. Journal of Neuroscience, 35, 7226-7238.

Brass, M., \& Haggard, P. (2007). To do or not to do: the neural signature of self-control. Journal of Neuroscience, 27, 9141-9145

Bray, E. E., MacLean, E. L., \& Hare, B. A. (2014). Context specificity of inhibitory control in dogs. Animal Cognition, 17, 15-31.

Bruyneel, S. D., Dewitte, S., Franses, P. H., \& Dekimpe, M. G. (2009). I felt low and my purse feels light: Depleting mood regulation attempts affect risk decision making. Journal of Behavioral Decision Making, 22, 153-170.

Carter, E. C., Kofler, L. M., Forster, D. E., \& McCullough, M. E. (2015). A series of metaanalytic tests of the depletion effect: self-control does not seem to rely on a limited resource. Journal of Experimental Psychology: General, 144, 796-815.

Carter, E. C., \& McCullough, M. E. (2014). Publication bias and the limited strength model of self-control: has the evidence for ego depletion been overestimated?. Frontiers in Psychology, 5, 823.

Carver, C. S., \& Harmon-Jones, E. (2009). Anger is an approach-related affect: evidence and implications. Psychological Bulletin, 135, 183-204.

Carver, C. S., \& Scheier, M. F. (1982). Control theory: A useful conceptual framework for personality-social, clinical, and health psychology. Psychological Bulletin, 92, 111-135. 
Carver, C. S., \& White, T. L. (1994). Behavioral inhibition, behavioral activation, and affective responses to impending reward and punishment: the BIS/BAS scales. Journal of Personality and Social Psychology, 67, 319-333.

Chester, D. S., \& DeWall, C. N. (2014). Prefrontal recruitment during social rejection predicts greater subsequent self-regulatory imbalance and impairment: Neural and longitudinal evidence. NeuroImage, 101, 485-493.

Chester, D. S., \& DeWall, C. N. (2015). The pleasure of revenge: retaliatory aggression arises from a neural imbalance toward reward. Social cognitive and affective neuroscience, 11, 1173-1182.

Christiansen, P., Cole, J. C., \& Field, M. (2012). Ego depletion increases ad-lib alcohol consumption: investigating cognitive mediators and moderators. Experimental and clinical psychopharmacology, 20, 118-128.

Clithero, J. A., \& Rangel, A. (2014). Informatic parcellation of the network involved in the computation of subjective value. Social Cognitive \& Affective Neuroscience, 9, 12891302.

Cloutier, J., Heatherton, T. F., Whalen, P. J., \& Kelley, W. M. (2008). Are attractive people rewarding? Sex differences in the neural substrates of facial attractiveness. Journal of Cognitive Neuroscience, 20, 941-951.

Cohen, M. X. (2011). It's about time. Frontiers in Human Neuroscience, 5, 2.

Corrigall, W. A., Franklin, K. B., Coen, K. M., \& Clarke, P. B. (1992). The mesolimbic dopaminergic system is implicated in the reinforcing effects of nicotine. Psychopharmacology, 107, 285-289. 
Cosme, D., Mobasser, A., Zeithamova, D., Berkman, E. T., \& Pfeifer, J. H. (2018). Choosing to regulate: does choice enhance craving regulation?. Social Cognitive and Affective Neuroscience, 13, 300-309.

Crowell, A., Kelley, N. J., \& Schmeichel, B. J. (2014). Trait approach motivation moderates the aftereffects of self-control. Frontiers in Psychology, 5, 1112.

Dambacher, F., Sack, A. T., Lobbestael, J., Arntz, A., Brugman, S., \& Schuhmann, T. (2014). The role of right prefrontal and medial cortex in response inhibition: Interfering with action restraint and action cancellation using transcranial magnetic brain stimulation. Journal of Cognitive Neuroscience, 26, 1775-1784.

Dang, J., Liu, Y., Liu, X., \& Mao, L. (2017). The Ego Could Be Depleted, Providing Initial Exertion Is Depleting. Social Psychology, 48, 242-245.

Demos, K. E., Kelley, W. M., \& Heatherton, T. F. (2011). Dietary restraint violations influence reward responses in nucleus accumbens and amygdala. Journal of Cognitive Neuroscience, 23, 1952-1963.

Demos, K. E., Heatherton, T. F., \& Kelley, W. M. (2012). Individual differences in nucleus accumbens activity to food and sexual images predict weight gain and sexual behavior. Journal of Neuroscience, 32, 5549-5552.

DeLuca, J., Genova, H. M., Hillary, F. G., \& Wylie, G. (2008). Neural correlates of cognitive fatigue in multiple sclerosis using functional MRI. Journal of the Neurological Sciences, 270, 28-39.

Denson, T. F., DeWall, C. N., \& Finkel, E. J. (2012). Self-control and aggression. Current Directions in Psychological Science, 21, 20-25. 
Denson, T. F., von Hippel, W., Kemp, R. I., \& Teo, L. S. (2010). Glucose consumption decreases impulsive aggression in response to provocation in aggressive individuals. Journal of Experimental Social Psychology, 46, 1023-1028.

DeWall, C. N., Baumeister, R. F., Stillman, T. F., \& Gailliot, M. T. (2007). Violence restrained: Effects of self-regulation and its depletion on aggression. Journal of Experimental social psychology, 43, 62-76.

DeWitt Huberts, J. C., Evers, C., \& De Ridder, D. T. (2012). License to sin: Self-licensing as a mechanism underlying hedonic consumption. European Journal of Social Psychology, $42,490-496$.

DeWitt Huberts, J. C., Evers, C., \& De Ridder, D. T. (2014). "Because I Am Worth It” A Theoretical Framework and Empirical Review of a Justification-Based Account of SelfRegulation Failure. Personality and Social Psychology Review, 18, 119-138.

Diekhof, E. K., \& Gruber, O. (2010). When desire collides with reason: functional interactions between anteroventral prefrontal cortex and nucleus accumbens underlie the human ability to resist impulsive desires. Journal of Neuroscience, 30, 1488-1493.

Dreisbach, G., \& Fischer, R. (2015). Conflicts as aversive signals for control adaptation. Current Directions in Psychological Science, 24, 255-260.

Druckerman, P. (September 12, 2014). Learning how to exert self-control. The New York Times. Retrieved from: https://www.nytimes.com/2014/09/14/opinion/sunday/learning-selfcontrol.html.

Eisenberger, R. (1992). Learned industriousness. Psychological review, 99, 248-267.

Eisenberger, R., Weier, F., Masterson, F. A., \& Theis, L. Y. (1989). Fixed-ratio schedules increase generalized self-control: Preference for large rewards despite high effort or 
punishment. Journal of Experimental Psychology: Animal Behavior Processes, 15, 383392.

Figner, B., Knoch, D., Johnson, E. J., Krosch, A. R., Lisanby, S. H., Fehr, E., \& Weber, E. U. (2010). Lateral prefrontal cortex and self-control in intertemporal choice. Nature Neuroscience, 13, 538-539

Finke, C., Schlichting, J., Papazoglou, S., Scheel, M., Freing, A., Soemmer, C., ... \& Ploner, C. J. (2015). Altered basal ganglia functional connectivity in multiple sclerosis patients with fatigue. Multiple Sclerosis Journal, 21, 925-934.

Finley, A. J., \& Schmeichel, B. J. (in press). Aftereffects of self-control on positive emotional reactivity. Personality and Social Psychology Bulletin.

Fischer, P., Greitemeyer, T., \& Frey, D. (2007). Ego depletion and positive illusions: Does the construction of positivity require regulatory resources?. Personality and Social Psychology Bulletin, 33(9), 1306-1321.

Fischer, P., Greitemeyer, T., \& Frey, D. (2008). Self-regulation and selective exposure: the impact of depleted self-regulation resources on confirmatory information processing. Journal of Personality and Social Psychology, 94, 382-395.

Fischer, P., Kastenmüller, A., \& Asal, K. (2012). Ego depletion increases risk-taking. The Journal of Social Psychology, 152(5), 623-638.

Freeman, N., \& Muraven, M. (2010). Self-control depletion leads to increased risk taking. Social Psychological and Personality Science, 1, 175-181.

Friese, M., Hofmann, W., \& Wänke, M. (2008). When impulses take over: Moderated predictive validity of explicit and implicit attitude measures in predicting food choice and consumption behaviour. British Journal of Social Psychology, 47, 397-419. 
Friese, M., Loschelder, D. D., Gieseler, K., Frankenbach, J., \& Inzlicht, M. (2018). Is ego depletion real? An analysis of arguments. Personality and Social Psychology Review, 1088868318762183 .

Furnham, A. (1984). The Protestant work ethic: A review of the psychological literature. European Journal of Social Psychology, 14, 87-104.

Furnham, A., Bond, M., Heaven, P., Hilton, D., Lobel, T., Masters, J., ... \& Van Daalen, H. (1993). A comparison of Protestant work ethic beliefs in thirteen nations. The Journal of Social Psychology, 133, 185-197.

Gailliot, M. T., Baumeister, R. F., DeWall, C. N., Maner, J. K., Plant, E. A., Tice, D. M., ... \& Schmeichel, B. J. (2007). Self-control relies on glucose as a limited energy source: willpower is more than a metaphor. Journal of Personality and Social Psychology, 92, $325-336$.

Galvan, A., Hare, T., Voss, H., Glover, G., \& Casey, B. J. (2007). Risk-taking and the adolescent brain: who is at risk?. Developmental Science, 10, 8-14.

Garrison, K. E., Crowell, A. L., Finley, A. J., \& Schmeichel, B. J. (2017). Effects of prior mental effort on picture processing: An ERP investigation. Psychophysiology, 54, 1714-1725.

Garrison, K., Finley, A. J., \& Schmeichel, B. (in press). Ego depletion reduces attention control: Evidence from two high-powered preregistered experiments. Personality and Social Psychology Bulletin.

Giuliani, N. R., Mann, T., Tomiyama, A. J., \& Berkman, E. T. (2014). Neural systems underlying the reappraisal of personally craved foods. Journal of Cognitive Neuroscience, 26, 1390-1402. 
Glazer, J. E., Kelley, N. J., Pornpattananangkul, N., Mittal, V. A., \& Nusslock, R. (2018).

Beyond the FRN: Broadening the time-course of EEG and ERP components implicated in reward processing. International Journal of Psychophysiology.

Gohm, C. L., \& Clore, G. L. (2000). Individual differences in emotional experience: Mapping available scales to processes. Personality and Social Psychology Bulletin, 26, 679-697.

Gujar, N., Yoo, S. S., Hu, P., \& Walker, M. P. (2011). Sleep deprivation amplifies reactivity of brain reward networks, biasing the appraisal of positive emotional experiences. Journal of Neuroscience, 31, 4466-4474.

Haber, S. N., \& Knutson, B. (2010). The reward circuit: linking primate anatomy and human imaging. Neuropsychopharmacology, 35, 4-26.

Hagger, M. S., Chatzisarantis, N. L., Alberts, H., Anggono, C. O., Batailler, C., Birt, A. R., ... \& Calvillo, D. P. (2016). A multilab preregistered replication of the ego-depletion effect. Perspectives on Psychological Science, 11, 546-573.

Hagger, M. S., Panetta, G., Leung, C. M., Wong, G. G., Wang, J. C., Chan, D. K., ... \& Chatzisarantis, N. L. (2013). Chronic inhibition, self-control and eating behavior: test of a 'resource depletion'model. PloS One, 8, e76888.

Hagger, M. S., Wood, C., Stiff, C., \& Chatzisarantis, N. L. (2010). Ego depletion and the strength model of self-control: A meta-analysis. Psychological bulletin, 136, 495-525.

Hämäläinen, M., Hari, R., Ilmoniemi, R. J., Knuutila, J., \& Lounasmaa, O. V. (1993). Magnetoencephalography - theory, instrumentation, and applications to noninvasive studies of the working human brain. Reviews of Modern Physics, 65, 413-497. 
Harmon-Jones, E., \& Gable, P. A. (2018). On the role of asymmetric frontal cortical activity in approach and withdrawal motivation: An updated review of the evidence. Psychophysiology, 55, e12879.

Harmon-Jones, E., \& Mills, J. (Eds.). (1999). Cognitive dissonance: Progress on a pivotal theory in social psychology. Washington, DC, US: American Psychological Association.

Haynes, A., Kemps, E., \& Moffitt, R. (2016). Too depleted to try? Testing the process model of ego depletion in the context of unhealthy snack consumption. Applied Psychology: Health and Well-Being, 8, 386-404.

Heatherton, T. F., \& Wagner, D. D. (2011). Cognitive neuroscience of self-regulation failure. Trends in Cognitive Sciences, 15, 132-139.

Hofmann, W., Baumeister, R. F., Förster, G., \& Vohs, K. D. (2012). Everyday temptations: an experience sampling study of desire, conflict, and self-control. Journal of Personality and Social Psychology, 102, 1318-1335.

Hofmann, W., Rauch, W., \& Gawronski, B. (2007). And deplete us not into temptation: Automatic attitudes, dietary restraint, and self-regulatory resources as determinants of eating behavior. Journal of Experimental Social Psychology, 43, 497-504.

Hofmann, W., Schmeichel, B. J., \& Baddeley, A. D. (2012). Executive functions and selfregulation. Trends in Cognitive Sciences, 16, 174-180.

Hughes, D. M., Yates, M. J., Morton, E. E., \& Smillie, L. D. (2014). Asymmetric frontal cortical activity predicts effort expenditure for reward. Social Cognitive and Affective Neuroscience, 10, 1015-1019.

Hutcherson, C. A., Bushong, B., \& Rangel, A. (2015). A neurocomputational model of altruistic choice and its implications. Neuron, 87, 451-462. 
Imhoff, R., Schmidt, A. F., \& Gerstenberg, F. (2014). Exploring the interplay of trait self-control and ego depletion: Empirical evidence for ironic effects. European Journal of Personality, 28, 413-424.

Inzlicht, M., Bartholow, B. D., \& Hirsh, J. B. (2015). Emotional foundations of cognitive control. Trends in Cognitive Sciences, 19, 126-132.

Inzlicht, M., Gervais, W., \& Berkman, E. (2015). Bias-Correction Techniques Alone Cannot Determine Whether Ego Depletion is Different from Zero: Commentary on Carter, Kofler, Forster, \& McCullough, 2015. Available at SSRN: http://ssrn.com/abstract=2659409 or http://dx.doi.org/10.2139/ssrn.2659409

Inzlicht, M., \& Gutsell, J. N. (2007). Running on empty: Neural signals for self-control failure. Psychological Science, 18, 933-937.

Inzlicht, M., \& Schmeichel, B. J. (2012). What is ego depletion? Toward a mechanistic revision of the resource model of self-control. Perspectives on Psychological Science, 7, 450-463.

Inzlicht, M., Schmeichel, B. J., \& Macrae, C. N. (2014). Why self-control seems (but may not be) limited. Trends in Cognitive Sciences, 18, 127-133.

Inzlicht, M., Shenhav, A., \& Olivola, C. (2017). The effort paradox: Effort is both costly and valued. Trends in Cognitive Sciences.

Jimura, K., Chushak, M. S., \& Braver, T. S. (2013). Impulsivity and self-control during intertemporal decision making linked to the neural dynamics of reward value representation. Journal of Neuroscience, 33, 344-357.

Jimura, K., Chushak, M. S., Westbrook, A., \& Braver, T. S. (2018). Intertemporal decisionmaking involves prefrontal control mechanisms associated with working memory. Cerebral Cortex, 28, 1105-1116. 
Kable, J. W., \& Glimcher, P. W. (2007). The neural correlates of subjective value during intertemporal choice. Nature Neuroscience, 10, 1625-1633.

Kelley, A. E., \& Berridge, K. C. (2002). The neuroscience of natural rewards: relevance to addictive drugs. Journal of Neuroscience, 22, 3306-3311.

Kelley, N. J., Glazer, J. E., Pornpattananangkul, N., \& Nusslock, R. (2019). Reappraisal and suppression emotion-regulation tendencies differentially predict reward-responsivity and psychological well-being. Biological Psychology, 140, 35-47.

Kelley, N. J., Hortensius, R., Schutter, D. J., \& Harmon-Jones, E. (2017). The relationship of approach/avoidance motivation and asymmetric frontal cortical activity: a review of studies manipulating frontal asymmetry. International Journal of Psychophysiology, 119, 19-30.

Kelley, W. M., Wagner, D. D., \& Heatherton, T. F. (2015). In search of a human self-regulation system. Annual Review of Neuroscience, 38, 389-411.

Kogan, N., \& Wallach, M. A. (1964). Risk taking: A study in cognition and personality. Oxford, UK: Holt, Rinehart \& Winston.

Kotabe, H. P., \& Hofmann, W. (2015). On integrating the components of selfcontrol. Perspectives on Psychological Science, 10, 618-638.

Kurzban, R. (2016). The sense of effort. Current Opinion in Psychology, 7, 67-70.

Kurzban, R., Duckworth, A., Kable, J. W., \& Myers, J. (2013). An opportunity cost model of subjective effort and task performance. Behavioral and Brain Sciences, 36, 661-679.

Kwong, K. K., Belliveau, J. W., Chesler, D. A., Goldberg, I. E., Weisskoff, R. M., Poncelet, B. P., ... \& Turner, R. (1992). Dynamic magnetic resonance imaging of human brain activity 
during primary sensory stimulation. Proceedings of the National Academy of Sciences, 89, 5675-5679.

Leknes, S., Brooks, J. C., Wiech, K., \& Tracey, I. (2008). Pain relief as an opponent process: a psychophysical investigation. European Journal of Neuroscience, 28, 794-801.

Lejuez, C. W., Read, J. P., Kahler, C. W., Richards, J. B., Ramsey, S. E., Stuart, G. L., ... \& Brown, R. A. (2002). Evaluation of a behavioral measure of risk taking: the Balloon Analogue Risk Task (BART). Journal of Experimental Psychology: Applied, 8, 75.

Lopez, R. B., Chen, P. H. A., Huckins, J. F., Hofmann, W., Kelley, W. M., \& Heatherton, T. F. (2017). A balance of activity in brain control and reward systems predicts self-regulatory outcomes. Social Cognitive and Affective Neuroscience, 12, 832-838.

Lopez, R. B., Hofmann, W., Wagner, D. D., Kelley, W. M., \& Heatherton, T. F. (2014). Neural predictors of giving in to temptation in daily life. Psychological Science, 25, 1337-1344.

Lopez, R. B., Milyavskaya, M., Hofmann, W., \& Heatherton, T. F. (2016). Motivational and neural correlates of self-control of eating: a combined neuroimaging and experience sampling study in dieting female college students. Appetite, 103, 192-199.

Luck, S.J. (2014). An introduction to the event-related potential technique ( $2^{\text {nd }}$ ed.). Cambridge, MA: The MIT Press.

Luethi, M. S., Friese, M., Binder, J., Boesiger, P., Luechinger, R., \& Rasch, B. (2016). Motivational incentives lead to a strong increase in lateral prefrontal activity after selfcontrol exertion. Social Cognitive and Affective Neuroscience, 11, 1618-1626.

Ma, Q., Meng, L., Wang, L., \& Shen, Q. (2014). I endeavor to make it: Fffort increases valuation of subsequent monetary reward. Behavioural Brain Research, 261, 1-7. 
MacLean, E. L., Hare, B., Nunn, C. L., Addessi, E., Amici, F., Anderson, R. C., ... \& Boogert, N. J. (2014). The evolution of self-control. Proceedings of the National Academy of Sciences, 111, E2140-E2148.

McClure, S. M., Ericson, K. M., Laibson, D. I., Loewenstein, G., \& Cohen, J. D. (2007). Time discounting for primary rewards. Journal of Neuroscience, 27, 5796-5804.

McClure, S. M., Laibson, D. I., Loewenstein, G., \& Cohen, J. D. (2004). Separate neural systems value immediate and delayed monetary rewards. Science, 306(5695), 503-507.

Meyer, H. C., \& Bucci, D. J. (2016). Imbalanced activity in the orbitofrontal cortex and nucleus accumbens impairs behavioral inhibition. Current Biology, 26, 2834-2839.

Miller, H. C., Pattison, K. F., DeWall, C. N., Rayburn-Reeves, R., \& Zentall, T. R. (2010). Selfcontrol without a "self”?: Common self-control processes in humans and dogs. Psychological Science, 21, 534-538.

Milyavskaya, M., Inzlicht, M., Hope, N., \& Koestner, R. (2015). Saying “no” to temptation: Want-to motivation improves self-regulation by reducing temptation rather than by increasing self-control. Journal of Personality and Social Psychology, 109, 677-693.

Milyavskaya, M., Inzlicht, M., Johnson, T., \& Larson, M. (2017). Reward sensitivity following boredom and cognitive effort: A high-powered neurophysiological investigation. bioRxiv, 177220.

Mischel, W. (1958). Preference for delayed reinforcement: An experimental study of a cultural observation. Journal of Abnormal and Social Psychology, 56, 57-61.

Mischel, W., Ebbesen, E. B., \& Zeiss, A. R. (1972). Cognitive and attentional mechanisms in delay of gratification. Journal of personality and Social Psychology, 21, 204-218. 
Moreno, S. G., Sutton, A. J., Ades, A. E., Stanley, T. D., Abrams, K. R., Peters, J. L., \& Cooper, N. J. (2009). Assessment of regression-based methods to adjust for publication bias through a comprehensive simulation study. BMC Medical Research Methodology, 9, 2.

Munakata, Y., Snyder, H. R., \& Chatham, C. H. (2012). Developing Cognitive Control Three Key Transitions. Current Directions in Psychological Science, 21, 71-77.

Muraven, M., \& Baumeister, R. F. (2000). Self-regulation and depletion of limited resources: Does self-control resemble a muscle?. Psychological Bulletin, 126, 247-259.

Muraven, M., Collins, R. L., \& Neinhaus, K. (2002). Self-control and alcohol restraint: An initial application of the Self-Control Strength Model. Psychology of Addictive Behaviors, 16, 113-120.

Muraven, M., Shmueli, D., \& Burkley, E. (2006). Conserving self-control strength. Journal of Personality and Social Psychology, 91, 524-537.

Noble, E. (1996). Alcoholism and the dopaminergic system: a review. Addiction biology, 1, 333348.

Osgood, J. M., \& Muraven, M. (2015). Self-control depletion does not diminish attitudes about being prosocial but does diminish prosocial behaviors. Basic and Applied Social Psychology, 37, 68-80.

Paulus, F. M., Rademacher, L., Schäfer, T. A. J., Müller-Pinzler, L., \& Krach, S. (2015). Journal impact factor shapes scientists' reward signal in the prospect of publication. PloS one, 10, $\mathrm{e} 0142537$.

Petit, O., Merunka, D., Anton, J. L., Nazarian, B., Spence, C., Cheok, A. D., ... \& Oullier, O. (2016). Health and pleasure in consumers' dietary food choices: Individual differences in the brain's value system. PloS one, 11, e0156333. 
Pfeifer, J. H., \& Berkman, E. T. (2018). The Development of Self and Identity in Adolescence: Neural Evidence and Implications for a Value-Based Choice Perspective on Motivated Behavior. Child Development Perspectives.

Pfurtscheller, G., Stancak Jr, A., \& Neuper, C. (1996). Post-movement beta synchronization. A correlate of an idling motor area?. Electroencephalography and Clinical Neurophysiology, 98, 281-293.

Pornpattananangkul, N., \& Nusslock, R. (2015). Motivated to win: Relationship between anticipatory and outcome reward-related neural activity. Brain and Cognition, 100, 2140.

Prinsen, S., Evers, C., Wijngaards, L., van Vliet, R., \& de Ridder, D. (2018). Does SelfLicensing Benefit Self-Regulation Over Time? An Ecological Momentary Assessment Study of Food Temptations. Personality and Social Psychology Bulletin, 0146167218754509.

Rapuano, K. M., Huckins, J. F., Sargent, J. D., Heatherton, T. F., \& Kelley, W. M. (2015). Individual differences in reward and somatosensory-motor brain regions correlate with adiposity in adolescents. Cerebral Cortex, 26, 2602-2611.

Reed, W. R. (2015). A Monte Carlo analysis of alternative meta-analysis estimators in the presence of publication bias. Economics: The Open-Access, Open-Assessment E-Journal, 9 (2015-30): 1-40.

Rosenthal , R. W. ( 1981 ). Games of perfect information, predatory pricing and the chain store paradox . Journal of Economic Theory, 25 , $92-100$. 
Rothermund, K., Voss, A., \& Wentura, D. (2008). Counter-regulation in affective attentional biases: a basic mechanism that warrants flexibility in emotion and motivation. Emotion, 8, 34-46.

Russell, B. (2004). History of western philosophy. London: Routledge.

Sanes, J. N., \& Donoghue, J. P. (1993). Oscillations in local field potentials of the primate motor cortex during voluntary movement. Proceedings of the National Academy of Sciences, 90, 4470-4474.

Saunders, B., Lin, H., Milyavskaya, M., \& Inzlicht, M. (2017). The emotive nature of conflict monitoring in the medial prefrontal cortex. International Journal of Psychophysiology, 119, 31-40.

Schlauch, R. C., Christensen, R. L., Derrick, J. L., Crane, C. A., \& Collins, R. L. (2015). Individual Differences in Approach and Avoidance Inclinations Moderate the Effect of Self-Control Depletion on Ad-Lib Drinking. Alcoholism: Clinical and Experimental Research, 39, 2480-2488.

Schmeichel, B. J. (2007). Attention control, memory updating, and emotion regulation temporarily reduce the capacity for executive control. Journal of Experimental Psychology: General, 136, 241-255.

Schmeichel, B. J., Crowell, A., \& Harmon-Jones, E. (2015). Exercising self-control increases relative left frontal cortical activation. Social Cognitive and Affective Neuroscience, 11, $282-288$.

Schmeichel, B. J., Harmon-Jones, C., \& Harmon-Jones, E. (2010). Exercising self-control increases approach motivation. Journal of Personality and Social Psychology, 99, 162173. 
Schmeichel, B. J., \& Vohs, K. (2009). Self-affirmation and self-control: affirming core values counteracts ego depletion. Journal of Personality and Social Psychology, 96(4), 770-782.

Schmidt, B., Mussel, P., Osinsky, R., Rasch, B., Debener, S., \& Hewig, J. (2017). Work first then play: Prior task difficulty increases motivation-related brain responses in a risk game. Biological Psychology, 126, 82-88.

Searle, J. (2001). Rationality in action. Cambridge, MA.: MIT Press.

Sescousse, G., Caldú, X., Segura, B., \& Dreher, J. C. (2013). Processing of primary and secondary rewards: a quantitative meta-analysis and review of human functional neuroimaging studies. Neuroscience \& Biobehavioral Reviews, 37, 681-696.

Shamosh, N. A., \& Gray, J. R. (2008). Delay discounting and intelligence: A metaanalysis. Intelligence, 36, 289-305.

Shamosh, N. A., DeYoung, C. G., Green, A. E., Reis, D. L., Johnson, M. R., Conway, A. R., ... \& Gray, J. R. (2008). Individual differences in delay discounting: relation to intelligence, working memory, and anterior prefrontal cortex. Psychological Science, 19, 904-911.

Shmueli, D., \& Prochaska, J. J. (2009). Resisting tempting foods and smoking behavior: Implications from a self-control theory perspective. Health Psychology, 28, 300-306.

Simonsohn, U. (2017, April 12). PET-PEESE is not like homeopathy [Web log comment]. Retrieved from http://datacolada.org/59.

Solomon, R. L. (1980). The opponent-process theory of acquired motivation: the costs of pleasure and the benefits of pain. American Psychologist, 35, 691-712.

Solomon, R. L., \& Corbit, J. D. (1974). An opponent-process theory of motivation: I. Temporal dynamics of affect. Psychological Review, 81, 119-145. 
Smith, D. G., \& Robbins, T. W. (2013). The neurobiological underpinnings of obesity and binge eating: a rationale for adopting the food addiction model. Biological Psychiatry, 73, 804810.

Steinberg, L. (2010). A dual systems model of adolescent risk-taking. Developmental Psychobiology, 52, 216-224.

Strait, C. E., Blanchard, T. C., \& Hayden, B. Y. (2014). Reward value comparison via mutual inhibition in ventromedial prefrontal cortex. Neuron, 82, 1357-1366.

Stucke, T. S., \& Baumeister, R. F. (2006). Ego depletion and aggressive behavior: Is the inhibition of aggression a limited resource?. European Journal of Social Psychology, 36, $1-13$.

Tabibnia, G., Monterosso, J. R., Baicy, K., Aron, A. R., Poldrack, R. A., Chakrapani, S., ... \& London, E. D. (2011). Different forms of self-control share a neurocognitive substrate. Journal of Neuroscience, 31, 4805-4810.

Threadgill, A. H., \& Gable, P. A. (2018a). Resting beta activation and trait motivation: Neurophysiological markers of motivated motor-action preparation. International Journal of Psychophysiology, 127, 46-51.

Threadgill, A. H., \& Gable, P. A. (2018b). Anger Enhances the RewP to Approach-Motivated Revenge and Aggravation. Manuscript submitted for publication.

Tough, P. (September 25, 2009). Can the Right Kinds of Play Teach Self-Control? The New York Times. Retrieved from: https://www.nytimes.com/2009/09/27/magazine/27tools-t.html. Underwood, B. J. (1975). Individual differences as a crucible in theory construction. American Psychologist, 30, 128-134. 
Vaughn, B. E., Kopp, C. B., \& Krakow, J. B. (1984). The emergence and consolidation of selfcontrol from eighteen to thirty months of age: Normative trends and individual differences. Child Development, 55, 990-1004.

Vijayakumar, N., Whittle, S., Yücel, M., Dennison, M., Simmons, J., \& Allen, N. B. (2014). Prefrontal structural correlates of cognitive control during adolescent development: a 4year longitudinal study. Journal of Cognitive neuroscience, 26, 1118-1130.

Vohs, K. D., \& Baumeister, R. F. (2016). Handbook of self-regulation: Research, theory, and applications $\left(3^{\text {rd }}\right.$ Ed.). New York, NY: Guilford Publications.

Vohs, K., Baumeister, R., Mead, N., Ramanathan, S., \& Schmeichel, B. (2011). Engaging in Self-Control Intensifies Desires and Feelings. ACR North American Advances.

Vohs, K. D., Baumeister, R. F., Schmeichel, B. J., Twenge, J. M., Nelson, N. M., \& Tice, D. M. (2008). Making Choices Impairs Subsequent Self-Control: A Limited-Resource Account of Decision Making, Self-Regulation, and Active Initiative. Journal of Personality and Social Psychology, 94, 883-898.

Vohs, K. D., \& Heatherton, T. F. (2000). Self-regulatory failure: A resource-depletion approach. Psychological science, 11, 249-254.

Wagner, D. D., Altman, M., Boswell, R. G., Kelley, W. M., \& Heatherton, T. F. (2013). Selfregulatory depletion enhances neural responses to rewards and impairs top-down control. Psychological Science, 24, 2262-2271.

Wagner, D. D., \& Heatherton, T. F. (2012). Self-regulatory depletion increases emotional reactivity in the amygdala. Social Cognitive and Affective Neuroscience, 8, 410-417.

Wagner, D. D., \& Heatherton, T. F. (2017). The Cognitive Neuroscience of Self-Regulatory Failure. Handbook of Self-Regulation: Research, Theory, and Applications, 111. 
Wang, Y., Yang, L. , \& Wang, Y. (2014). Suppression (but Not Reappraisal) Impairs subsequent error detection: An ERP study of emotion regulation's resource-depleting effect. PloS One, 9, e96339.

Weber, M. (1958). The Protestant ethic and the spirit of capitalism. New York: Scribner.

Westbrook, A., Kester, D., \& Braver, T. S. (2013). What is the subjective cost of cognitive effort? Load, trait, and aging effects revealed by economic preference. PloS One, 8 , e68210.

Wiesner, C. D., \& Lindner, C. (2017). Weakening self-control biases the emotional evaluation of appetitive cues. PloS One, 12(1), e0170245.

Wilson, S. J., Sayette, M. A., \& Fiez, J. A. (2013). Neural correlates of self-focused and otherfocused strategies for coping with cigarette cue exposure. Psychology of Addictive Behaviors, 27, 466-476.

Wise, R. A. (2004). Dopamine, learning and motivation. Nature Reviews Neuroscience, 5, 483494.

Young, C. B., \& Nusslock, R. (2016). Positive mood enhances reward-related neural activity. Social Cognitive and Affective Neuroscience, 11, 934-944

Zentall, T. R. (2010). Justification of effort by humans and pigeons: cognitive dissonance or contrast?. Current Directions in Psychological Science, 19, 296-300. 


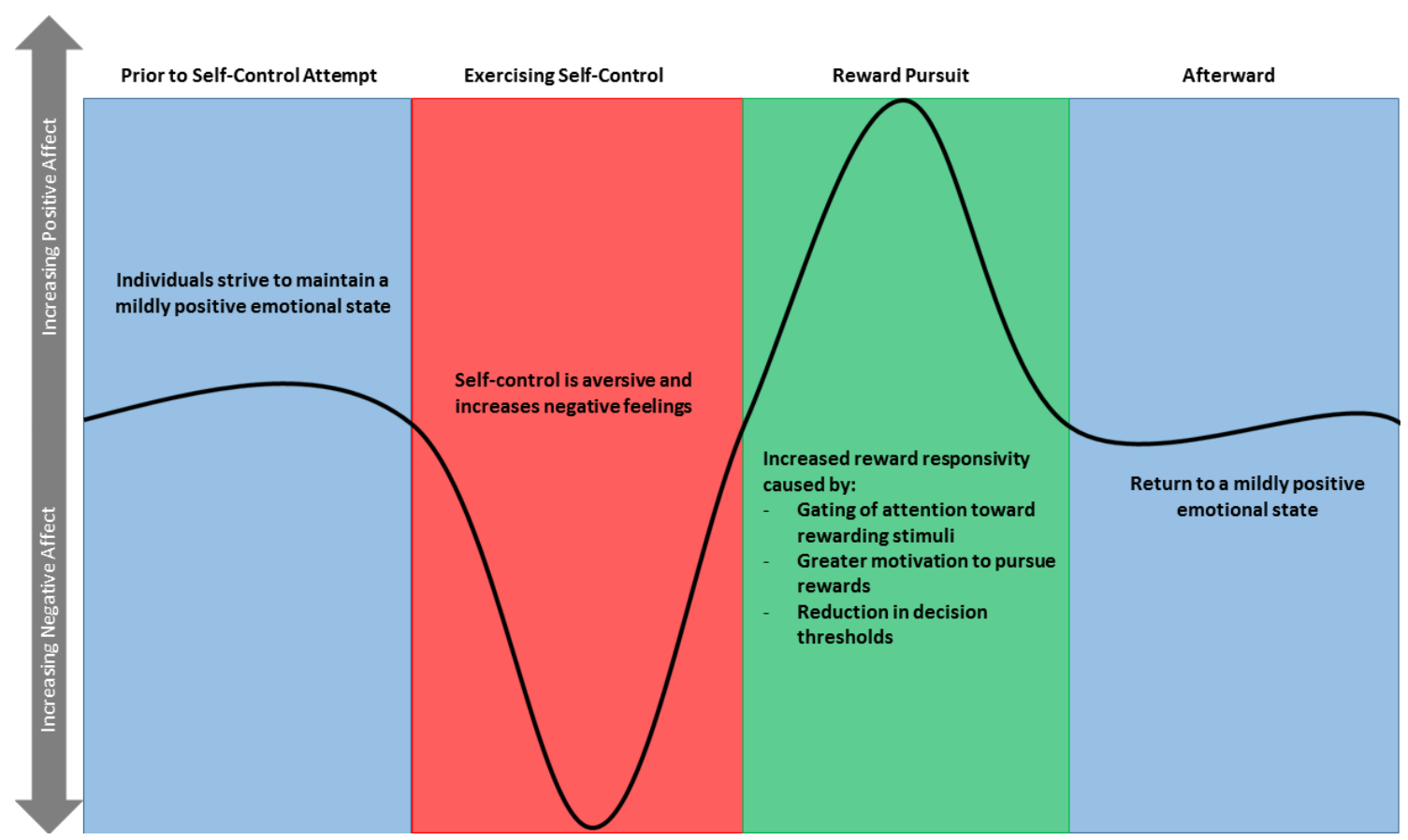

Figure 1. The reward responsivity hypothesis. This figure draws heavily from an opponentprocess framework of motivation (Solomon, 1980; Solomon \& Corbit, 1974). Panel (A): The baseline assumption is that individuals strive to maintain a mildly positive emotional state. Panel (B): Exerting self-control is effortful and phenomenologically aversive, leading to a negative emotional state. Panel (C): Reward responsivity increases after exerting self-control, resulting in shifts in attention and motivation that reduce thresholds for reward-pursuing action. Panel (D): The positive emotions that attend the pursuit and receipt of rewards counters the negative emotional state associated with exerting self-control, thereby returning individuals to a mildly positive emotional state. 